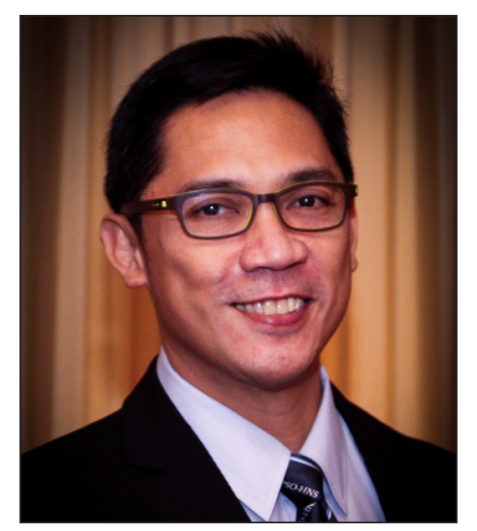

\title{
Opening the PJO-HNS to the Country and to the World
}

As our different training institutions from north to south of the archipelago strive to push their research agenda to the forefront, it is only imperative for the Philippine Society of Otolaryngology-Head and Neck Surgery to provide the platform for their research output to be documented, published and shared with the rest of the scientific community.

And towards this end, the Philippine Journal of Otolaryngology-Head and Neck Surgery has not only met the expectations of our dear fellows and trainees but has far exceeded them.

Congratulations to the contributing authors and institutions and kudos to the editorial staff headed by Dr. Jose Florencio Lapeña. With all the laudable achievements it has accomplished, PJO-HNS needs all our support to see it through its continuous journey of improvement and development into an open access journal.

As we bring 2017 to a close, on behalf of the Board of Trustees of the PSO-HNS, I wish you all the very best for the new year to come.

MELFRED L. HERNANDEZ, MD, MHA

President

Philippine Society of Otolaryngology-Head and Neck Surgery 